University of Nebraska - Lincoln

DigitalCommons@University of Nebraska - Lincoln

March 2000

\title{
Interactive Worksheets in Large Introductory Physics Courses
}

Diandra Leslie-Pelecky

University of Nebraska -- Lincoln, diandra2@unl.edu

Follow this and additional works at: https://digitalcommons.unl.edu/physicslesliepelecky

Part of the Physics Commons

Leslie-Pelecky, Diandra, "Interactive Worksheets in Large Introductory Physics Courses" (2000). Diandra Leslie-Pelecky Publications. 16.

https://digitalcommons.unl.edu/physicslesliepelecky/16

This Article is brought to you for free and open access by the Research Papers in Physics and Astronomy at DigitalCommons@University of Nebraska - Lincoln. It has been accepted for inclusion in Diandra Leslie-Pelecky Publications by an authorized administrator of DigitalCommons@University of Nebraska - Lincoln. 


\title{
Interactive Worksheets in Large Introductory Physics Courses
}

\author{
Diandra L. Leslie-Pelecky, Department of Physics \& Astronomy and Center for Materials Research \& \\ Analysis, University of Nebraska-Lincoln, Lincoln, NE 68588-0111; diandra2@ unl.edu
}

$\mathbf{P}$ hysics education research indicates that interactive instruction techniques improve student performance. ${ }^{1}$ A variety of methods have been developed to promote interactivity, including peer instruction, ${ }^{2}$ tutorials, ${ }^{3}$ ranking tasks, ${ }^{4}$ and in-class worksheets. ${ }^{5}$ These techniques are attractive because they are adaptable to classes of all sizes and rarely require the instructor to make radical changes in the course content or pedagogical approach.

Our Physics 151 is a one-semester algebra-based course for which the primary audience is architecture, construction management, natural resources, and business majors. Eighty to 140 students are in each section. The course has three hours of lecture and one hour of recitation each week, but no laboratory component.

I had twice used peer instruction as popularized by Mazur, ${ }^{2}$ where the instructor poses a multiple-choice question and students are given a minute or two to choose and display their answers using flashcards ${ }^{6}$ or an electronic response system. One to two minutes are allotted for students to discuss the problem in small groups, and a second show of answers is requested. I found this technique to be a significant improvement over "passive" lectures, but I had concerns. Mazur's questions are tailored to the traditional two-semester physics course and were too abstract for many of my students. Writing "good" questions- those that stimulate thought and identify misconceptions-is not easy. My questions met with varied degrees of success and took a significant amount of time to write. Furthermore, about a quarter of the students refused to participate in the show of answers using flashcards. A smaller percentage did not want to participate in group discussions. The primary reason for their reluctance (cited by the students) was embarrassment that others would see if they were wrong. Most significantly, feedback with the peer instruction method told me when students didn't understand a concept, but couldn't always indicate why they were confused.

Adapting a different technique would be worthwhile only if the new technique offered significant improvements. The alternative that appeared most likely to meet these demands was using in-class worksheets. Worksheets are very versatile and can be tailored to meet specific goals. For the spring 1998 offering of Physics 151, we completed one worksheet each week. The 11 worksheets counted for $1 / 8$ of the total class grade. Students were not allowed to make up the worksheets, were not told in advance when the worksheets would be handed out, and although students worked in groups of three or four, each person was required to turn in his or her own worksheet. They were graded and returned, to be compared with posted solutions.

\section{Worksheet Structure}

Physics 151 is somewhat different from other physics courses in that it lasts only one semester and the instructor has some latitude in choosing the topics to include. I chose to focus on topics of interest to architects and construction management engineers, since they made up the majority of the class. This meant that many existing sources for worksheets $^{3-5}$ could not be used without modifications and/or additions. So I wrote my own worksheets, which allowed me to target very specific goals I had established for the class.

Worksheets were of two types. Problem-solving worksheets were designed to lead students through the specific steps for arriving at an algebraic or numerical answer. The problem selected was often one I would have worked as a sample problem during the lecture.

The second type of worksheet was focused more on developing conceptual understanding and confronting student preconceptions. Particularly effective examples of this type were exercises teaching the students that charge is not "used up" in an electric circuit and that the normal force on an object is not necessarily equal to the object's weight. Worksheets were generally used to establish the skills and concepts necessary for understanding subsequent material. For example, one worksheet emphasized drawing free-body diagrams for a variety of carefully chosen situations. My worksheets are similar in nature 
to van Heuvelen's, ${ }^{5}$ but don't have a multimedia component.

I alternated between introducing a topic, allowing the students 10-15 minutes to work on part of the worksheet, then taking another 5-10 minutes to either clarify the problem on which they had been working, or to introduce material necessary for the next part of the worksheet. The ability to stop the class at any point to clarify a common misconception is invaluable in keeping the students from getting a wrong idea too firmly implanted in their heads. While the groups worked, I moved about the room asking and answering questions.

\section{Student Response}

When students were surveyed anonymously at the end of the semester about the effectiveness of the worksheets, reaction was overwhelmingly positive, though upper-class students were in general less positive about the different format than firstand second-year students. Of the students who expressed negative opinions, most didn't like the fact that the worksheets were part of their course grade, which limited their ability to skip class without being penalized. Some of the quicker students were frustrated when they finished the worksheets and had to wait for everyone else to catch up.

The evaluations identified two primary problems. The first was that the students often felt hurried. I have become better at estimating how long each exercise should take.

The second primary complaint concerned grades. Many students felt that, given the limited time available for the worksheets, grading should be more on the basis of participation and less on the actual answers. (An analysis of the final grades showed that the only students whose letter grades were lowered because of their worksheet score were those who were absent from class for several worksheets.) Despite concerns about grades, students felt very strongly that the worksheets should be collected and graded, as opposed to just posting a solution.

When asked to compare worksheets and homework, students preferred the worksheets as a means of learning how to do problems. Part of this preference likely is due to the worksheets being written by the instructor: there was more similarity between the exams and the worksheets than between the exams and the homework problems in the book.

There was some stated frustration that there was only one person circulating among 110 students while they were completing the worksheets. The worksheet idea was novel enough that semester that some faculty and postdocs volunteered to help during worksheet days to see how the technique worked. This lessened the problem, but the large student-toteacher ratio remains a challenging issue.

\section{The Instructor's Evaluation}

Of the three requirements I had for adopting a new technique, the requirement of getting detailed information on both when students were not understanding the material and why they were confused was fulfilled the best. The immediate student feedback allowed me to confront student preconceptions and incorrect conclusions drawn from lecture on the spot. I felt I had a much better evaluation of how the class was going on a daily basis.

The other two requirements-not to take significantly more instructor time and to improve student participation-turned out to be orthogonal to each other. Grading the worksheets and making them a non-negligible portion of the student's grade ensured a high level of participation. Previous experience teaching this course suggested that a 60 to $75 \%$ attendance would be likely on any given day; however, the number of worksheets graded shows that the average class attendance was more like 80 to $90 \%$. It took me from one to three hours to grade 115 worksheets.

I covered slightly less material than in previous semesters, but this was not due solely to the use of worksheets. I purposely focused on a narrower range of subjects, asking the students to solve more difficult problems within the range of subjects covered. Physics 151 is a stand-alone course, so providing knowledge necessary for the next semester was not a primary concern.

An unanticipated benefit of the technique was that the psychological distance between student and teacher that is often present in large classes was mostly eliminated. Students' names were at the top of each page of their worksheet, so I always knew to whom I was speaking when I was moving about the classroom. I got to know a much larger fraction of the students, which encouraged more students to seek help during office hours.

\section{Use in Another Course}

Last fall, a colleague (R. Hilborn) used similar worksheets in a secondsemester introductory course for engineering and physics majors. The course emphasized interactive engagement more heavily than my 151 class, including not only worksheets, but also preclass web testing and context-rich problem-solving sessions. Twenty-three worksheets were completed during the 30 classes of the semester.

Student reaction was similar to that of the noncalculus-based class. Students generally valued doing worksheets, although some thought that the worksheets should be related even more directly to the homework. A few complained that worksheets took time away from the instructor doing example problems. The instructor felt that the worksheets helped students learn how to break a problem into tractable pieces, and thus improved not only their understanding of specific material, but also their overall problem-solving skills. 


\section{Lessons Learned}

Worksheets are very effective at confronting preconceptions, ensuring class participation, and increasing student/teacher interaction. Designing a worksheet with a problem that can be broken into parts can help a teacher determine whether the difficulty is the mathematics (e.g., solving quadratic equations) or in the conceptual understanding (identifying the principles that lead to the equation to be solved). Open-answer questions that are too vague, however, will produce answers that do not provide the teacher with useful information and are very hard to grade. Once you have written a satisfactorily focused question, give students lots of space to write. Since students usually write first and think second, they may scribble out their first answers.
Worksheets are not conducive to neatness! Worksheet feedback can identify weaknesses in a teacher's presentation of the topic and be very valuable in showing the novice teacher how to be more explicit in lecture.

In summary, I found that any disadvantages with the method are more than offset by my perception that the students were working harder, learning concepts better, and were more motivated than in other settings I had tried. Our experience indicates that worksheets are a versatile tool that can be tailored to emphasize those skills or concepts the instructor determines to be important.

\section{References}

1. Richard R. Hake, "Interactive engagement versus traditional methods: A six-thousand stu- dent survey of mechanics test data for introductory physics courses," Am. J. Phys. 66, 6474 (1997).

2. Eric Mazur, Peer Instruction: A User's Manual (Prentice-Hall, Upper Saddle River, NJ, 1996).

3. Lillian C. McDermott and Peter S. Shaffer, Tutorials in Physics, preliminary ed. (Prentice Hall, Upper Saddle River, NJ, 1997).

4. Ranking Task Exercises in Physics, edited by T. L. O'Kuma, D. P. Maloney, and C. J. Hieggelke (Prentice-Hall, Upper Saddle River, NJ, 1999).

5. Alan Van Heuvelen, ActivPhysics (Addison Wesley, 1997).

6. David E. Meltzer and Kandiah Manivannan, "Promoting interactivity in physics lecture classes," Phys. Teach. 34, 72 (1996). 